\title{
Investigation of local meteorological events and their relationship with ozone and aerosols during an ESCOMPTE photochemical episode
}

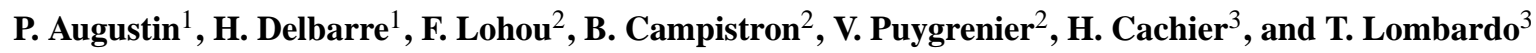 \\ ${ }^{1}$ Laboratoire de Physico-Chimie de l'Atmosphère, UMR CNRS 8101, Université du Littoral-Côte d'Opale, 189A, Avenue M. \\ Schumann, 59140 Dunkerque, France \\ ${ }^{2}$ Laboratoire d'Aérologie, UMR 5560 CNRS/OMP/UPS, Centre de Recherches Atmosphériques, 65300 Campistrous, France \\ ${ }^{3}$ Laboratoire des Sciences du Climat et de l'Environnement, UMR CNRS-CEA 1572, avenue de la Terrasse, 91198 Gif sur \\ Yvette, France
}

Received: 11 April 2006 - Revised: 8 September 2006 - Accepted: 20 September 2006 - Published: 21 November 2006

\begin{abstract}
The international ESCOMPTE campaign, which took place in summer 2001 in the most highly polluted French region, was devoted to validate air pollution prediction models. Surface and remote sensing instruments $(\mathrm{Li}-$ dar, Radar and Sodar) were deployed over the Marseille area, along the Mediterranean coast, in order to investigate the fine structure of the sea-breeze circulation and its relationship with the pollutant concentrations.

The geographical situation of the Marseille region combines a complex coastline and relief which both lead to a peculiar behaviour of the sea-breeze circulation. Several local sea breezes, perpendicular to the nearest coastline, settled in during the morning. In the afternoons, when the thermal gradient between the continental and marine surface grows up, a southerly or a westerly sea breeze may dominate. Their respective importance is then a function of time, space and altitude. Furthermore, an oscillation of the westerly sea breeze with a period of about $3 \mathrm{~h}$ is also highlighted.

We show that these dynamical characteristics have profound influences on the atmospheric boundary-layer (ABL) development and on pollutant concentrations. In fact, the direction and intensity of the sea-breeze determine the route and the transit time of the stable marine air flow over the continental surface. Thus, the ABL depth may exhibit several collapses correlated with the westerly sea-breeze pulsation. The ozone and aerosol concentrations are also related to the dynamical features. In the suburbs and parts of the city under pulsed sea breezes, a higher ABL depth and higher ozone concentrations are observed. In the city centre, this relationship between pulsed sea-breeze intensity and ozone concentration is different, emphasising the importance of the
\end{abstract}

Correspondence to: F. Lohou

(lohf@aero.obs-mip.fr) transit time and also the build-up of pollutants in the marine air mass along the route. Finally, the variations of aerosol concentration are also described according to the breeze direction.

Keywords. Atmospheric composition and structure (Aerosols and particles; Evolution of the atmosphere) Radio science (Remote sensing)

\section{Introduction}

Many dense industrial or urban regions are located in a geographical context where local meteorological phenomena strongly influence the air quality. Every site with its own geographical (coastline, relief...) and anthropogenic (urban, industrial areas) features may generate complex meteorological and chemical processes. This complexity motivated various international campaigns inside regions where the combination of relief and sea may amplify the pollution and act on its circulation and long-range transport: the MECAPIP and RECAPMA meso-meteorological cycle of air pollution in the Iberian Peninsula (Millán et al., 1996; Gangoiti et al., 2001), the MEDCAPHOT mediterranean campaign of photochemical tracers in the Athens area (Melas et al., 1998) or the NARE (North Atlantic Regional Experiment) in Nova Scotia (Angevine et al., 1996). The international ESCOMPTE campaign took place during summer 2001 in the region of Marseille-Berre, one of the most highly polluted French regions, in order to validate air pollution prediction models (Cros et al., 2004). Part of the project was devoted to the analysis of the dynamics of Marseille's Urban Boundary Layer (UBL) (Mestayer et al., 2005). Several ground-based remote sensing instruments, such as radars,

Published by Copernicus GmbH on behalf of the European Geosciences Union. 
sodars and lidars, were deployed over Marseille and its northern suburbs. Quasi-continuous monitoring of the lower troposphere was undertaken during four intensive observation periods of three days, associated with photochemical pollution events. Beyond the database development and model assessment, previous remote sensing and ground-based meteorological studies allowed the very complex behaviour of the lower troposphere to be highlighted. In the ESCOMPTE region, sea proximity with an irregular coastline, the large city and the surrounding relief are cumulative factors which increase the complexity of the troposphere dynamics. Analysis of the remote sensing measurements during a photochemical episode by Delbarre et al. (2005) (26 June 2001) showed that the dynamics may be partly explained by a changing seabreeze phenomenon, leading to an evolving multiple layer structure. Puygrenier et al. (2005) firstly observed the occurrence of a pulsed sea breeze and the consequences on internal boundary layer development; this is another phenomenon adding to the variation in sea-breeze direction. The pulsed breeze of northern Marseille has been partly explained by the combination of sea-breeze and slope effects (Bastin et al., 2005). These studies underline the major role of the local meteorological events on the lower troposphere dynamics and hence on the boundary layer behaviour. Pollution assessment in such complex geographical situations requires an understanding of the role of local meteorological mechanisms in pollution build-up. High resolution models now allow these complex dynamical behaviours to be reproduced (Lemonsu et al., 2006), but do not include the chemical processes at such a fine scale. What is the vertical pollutant distribution under sea-breeze variations? Does the sea-breeze pulsation exert an influence on the ozone and aerosols levels? What is the pollutant transfer between diverse layers under a complex stratification in the lower troposphere? Can we recognize the diverse meteorological dynamical mechanisms' influence on the gaseous and aerosol evolution? Through an ESCOMPTE photochemical pollution event distinguished by complex dynamical features, we investigate the role of local meteorological events on the spatial and temporal distributions of pollutants. Remote sensing instruments and local meteorological stations are used to analyse the induced complex stratification, in order to highlight the relevant meteorological mechanisms. The ozone vertical distribution is investigated by lidar measurements, together with ground-based ozone and aerosols measurements, to establish their relationship with local events.

\section{Experimental configuration}

ESCOMPTE and UBL experiments gave the opportunity to gather and deploy ground-based remote sensing systems over the Marseille area, such as ultraviolet and infrared lidars, radar and sodar, with the aim of characterizing the vertical structure and dynamics of the lower troposphere.
Radiosounding (RS), Constant Volume Balloon (CVB) and meteorological and chemical ground stations completed the measurement setup.

Figure 1 displays the location of the ground-based remote sensing and meteorological ground stations used in this study, focusing on Marseille's city and suburbs. The geographical situation combines a complex coastline and relief. The city is bordered by the sea both to the south and to the west and by topographical features to the south (Calanques ridge), south-east (Carpiagne Mountain) and north (Etoile ridge). The gap between south-east and north features is likely to induce a channel effect in the flow from the east.

\subsection{Surface stations}

Surface horizontal wind velocities were collected downtown by three meteorological stations located at Hippodrome (Hipp), Groupement des Laboratoires de Marseille (GLM) and Cour d'Appel Administrative de Marseille (CAAM). In the northern suburbs of Marseille, two sites were instrumented at Vallon Dol and St Jérôme. Finally, the southern dynamical conditions were recorded at the Cassis site, located S-E of the town on the other side of the Calanques ridge. The concentration of various pollutants was measured at "St Marguerite" and "5 Avenues" by the air quality network "Airmaraix" which controls regulated pollutants in the Marseille region. Locations, altitudes and distances from the southern and western coasts of these surface stations are given in Table 1.

\subsection{Remote-sensing experimental set}

A quasi-continuous monitoring of the boundary layer and lower troposphere was carried out by an ultraviolet lidar with pointing capability (UV lidar), an Ultra High-Frequency radar (UHF) and a sodar, all operating simultaneously.

\subsubsection{Angular ultraviolet lidar}

The UV lidar is a commercial lidar which has already been involved and evaluated in many previous air pollution campaigns (Kölsch et al., 1992; Kambezidis et al., 1998; Thomasson et al., 2002). This lidar was located at Vallon Dol $\left(43.36^{\circ} \mathrm{N}, 5.4^{\circ} \mathrm{E}\right)$ in the north of Marseille, at a $285 \mathrm{~m}$ a.s.l. altitude and about $5 \mathrm{~km}$ from the westerly coast. This Differential Absorption Lidar (DIAL) makes a continuous measurement of the $\mathrm{O}_{3}, \mathrm{SO}_{2}, \mathrm{NO}_{2}$, benzene or toluene concentration and the extinction coefficient in any chosen direction. The pollutant is selected by choosing the differential absorption wavelengths of a dual wavelength laser. The primary laser is a pulsed Ti:Sapphire infrared laser pumped by flashlamps. The optical frequency of each pulse is doubled and tripled in nonlinear LBO and BBO crystals, to generate 40ns ultraviolet pulses with a 3-4 mJ energy in the 250-290 nm wavelength range, and at a $20 \mathrm{~Hz}$ repetition rate. 


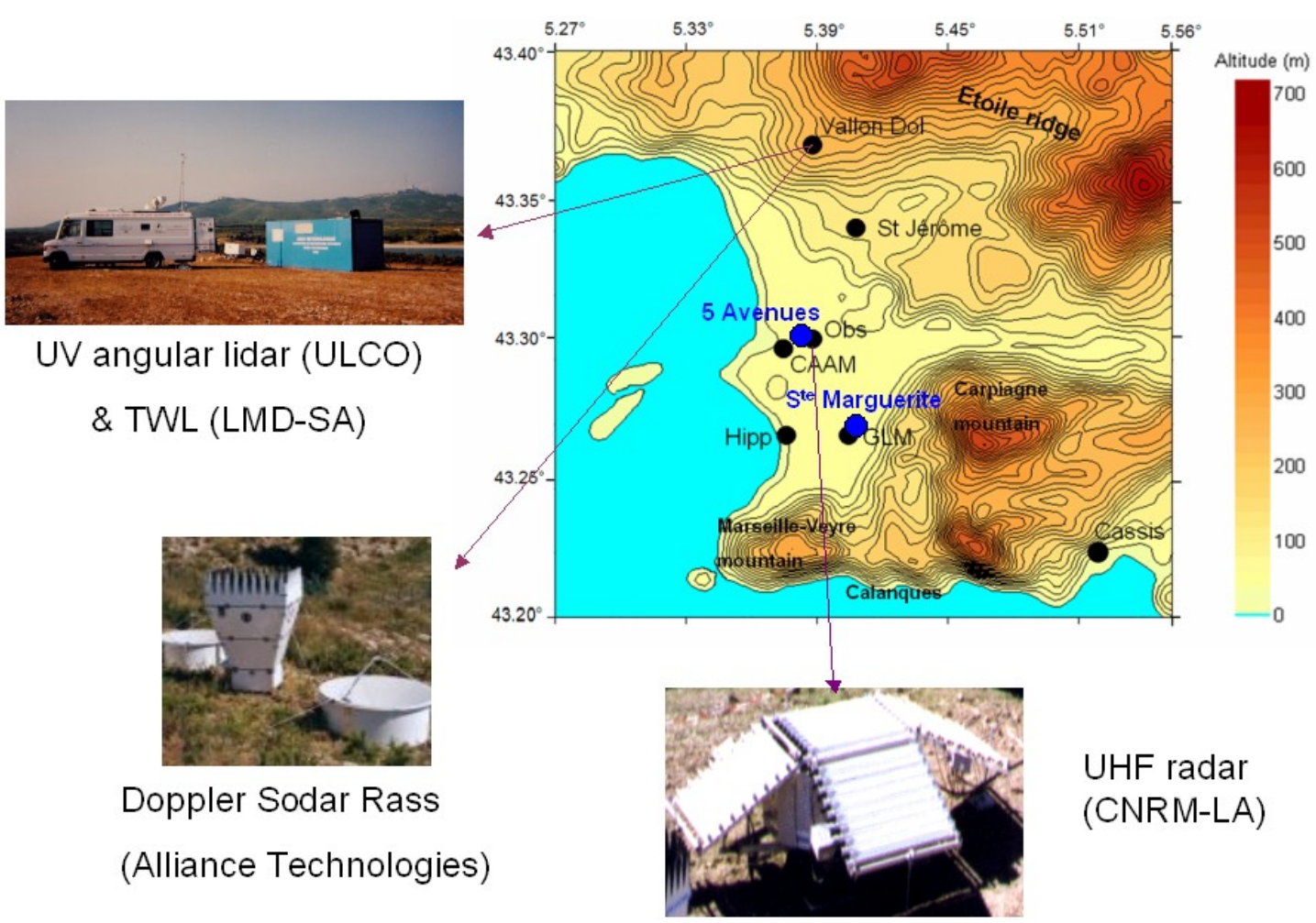

Fig. 1. Ground-based equipment for remote sensing in Marseille and its suburbs, and ground station locations at Vallon Dol, St Jérôme, Observatoire (Obs), Cour d'Appel Administrative de Marseille (CAAM), Groupement des Laboratoires de Marseille (GLM), Hippodrome (Hipp), Cassis, 5 Avenues and St Marguerite.

Table 1. Meteorological and air quality ground stations location in Marseille's area and the research laboratory in charge of conducting the investigations.

\begin{tabular}{lllllll}
\hline Sites & Longitude & Latitude & Altitude & $\begin{array}{l}\text { Distance to } \\
\text { southern coast }\end{array}$ & $\begin{array}{l}\text { Distance to } \\
\text { western coast }\end{array}$ & Laboratory in charge \\
\hline Vallon Dol & $5.40^{\circ} \mathrm{E}$ & $43.36^{\circ} \mathrm{N}$ & $\sim 285 \mathrm{~m}$ & $15 \mathrm{~km}$ & $5 \mathrm{~km}$ & Météo France/CNRM \\
St Jérôme & $5.41^{\circ} \mathrm{E}$ & $43.34^{\circ} \mathrm{N}$ & $130 \mathrm{~m}$ & $13.5 \mathrm{~km}$ & $6 \mathrm{~km}$ & LMF-CNRS/ECN \\
$\mathrm{CAAM}$ & $5.38^{\circ} \mathrm{E}$ & $43.30^{\circ} \mathrm{N}$ & $70 \mathrm{~m}$ & $9.5 \mathrm{~km}$ & $1.5 \mathrm{~km}$ & Indiana University \\
$\mathrm{GLM}$ & $5.41^{\circ} \mathrm{E}$ & $43.25^{\circ} \mathrm{N}$ & $32 \mathrm{~m}$ & $4.5 \mathrm{~km}$ & $3.2 \mathrm{~km}$ & Coria \\
Hipp & $5.38^{\circ} \mathrm{E}$ & $43.25^{\circ} \mathrm{N}$ & $12 \mathrm{~m}$ & $5 \mathrm{~km}$ & $0.5 \mathrm{~km}$ & Météo France \\
Cassis & $5.51^{\circ} \mathrm{E}$ & $43.22^{\circ} \mathrm{N}$ & $212 \mathrm{~m}$ & $2.5 \mathrm{~km}$ & $12.5 \mathrm{~km}$ & Météo France \\
St Marguerite & $5.41^{\circ} \mathrm{E}$ & $43.26^{\circ} \mathrm{N}$ & $36 \mathrm{~m}$ & $5 \mathrm{~km}$ & $3.2 \mathrm{~km}$ & AIRMARAIX \\
5 Avenues & $5.39^{\circ} \mathrm{E}$ & $43.30^{\circ} \mathrm{N}$ & $76 \mathrm{~m}$ & $10 \mathrm{~km}$ & $3 \mathrm{~km}$ & AIRMARAIX \\
\hline
\end{tabular}

This UV lidar continuously measured the ozone concentration and extinction during the four intensive observation periods of three days, from 15 June 2001 to 14 July 2001, except during time periods devoted to unavoidable calibration and optical realignment procedures. The backscattered lidar signals, and the ozone and extinction vertical distribution provide information both on the lower troposphere stratification and the pollutant distribution within the various layers. The techniques used in this way have been discussed in detail in a preceding study devoted to the analysis of the lower troposphere stratification and dynamics during an ESCOMPTE photochemical episode (Delbarre et al., 2005), so only the main features are presented here. The profiles from scans provided ozone concentration distribution along several consecutive beams with a $10^{\circ}$ angle of resolution in the vertical planes. Ozone concentration and extinction vertical maps were primarily performed along the north-south line.

The lidar blind distance (near field beam overlap) is $250 \mathrm{~m}$ and its maximum range is around $2 \mathrm{~km}$. Angular scans are performed within $30 \mathrm{~min}$, with a spatial resolution of about 
$100 \mathrm{~m}$ along each beam. The differential absorption wavelengths for ozone measurements were fixed, respectively, to 286.3 and $282.4 \mathrm{~nm}$, and the total extinction coefficient was determined using the $286.3 \mathrm{~nm}$ wavelength. The extinction is computed with the slope method, which assumes a slowly varying backscattering coefficient, as detailed in Delbarre et al. (2005). Under this assumption, the extinction is valid inside a given layer, providing it remains homogeneous. However, it should be noted that this assumption is not generally valid at the layer transitions and leads to an over- or under-estimated extinction, according to the transition type. Ozone and extinction vertical maps allow rapid layer identification, however, the final lower troposphere structure is determined by the one-dimensional lidar signals. The heights of the layers transitions are computed by using the inflexion point method (IPM) (Menut et al., 1999), relying upon the second derivative of the lidar signal to determine the signal shifts and slope variations when the laser beam crosses a layer transition. The lidar measurements allow the lower troposphere dynamics to be examined, by defining the location of the lower layers and the ozone and extinction within the layers. These measurements can be performed continuously during a photochemical episode.

\subsubsection{UHF wind profiler}

Four UHF wind profilers were deployed over the ESCOMPTE domain, in order to provide wind vertical profiles in the lower atmosphere with high temporal and spatial resolution in clear air and precipitating conditions. This UHF network consisted of several identical DEGREWIND PCL1300 instruments manufactured by Degreane. This study will use only the UHF profiler located in downtown Marseille at the Observatoire (Obs in Fig. 1). This five-beam wind profiler operated continuously during the campaign with a $1280 \mathrm{MHz}$ transmitted frequency, $4 \mathrm{~kW}$ peak power, $20 \mathrm{kHz}$ pulse repetition frequency and a $150 \mathrm{~m}$ pulse width. In order to obtain the three components of the wind, the profiler sequentially uses five beams, one vertical and four oblique, with a oneway, half-power aperture of $8.5^{\circ}$. The oblique beams, with an off-zenith angle of $17^{\circ}$, are oriented every $90^{\circ}$ in azimuth. A real-time beam spectral analysis gives the Doppler spectra at selected range gates from $75 \mathrm{~m}$ up to a height of about $3 \mathrm{~km}$, with a $75 \mathrm{~m}$ vertical resolution. The spectra, contaminated by noise and non-meteorological echoes, are carefully edited in order to select and extract the first three moments of the atmospheric peak: radar reflectivity, radial velocity, and spectral width. Data quality control and processing are performed through a consensus algorithm based on the time $(30 \mathrm{~min})$ and height continuity (three range gates) of the edited spectra. The zenith-pointing beam radial velocity provides air vertical velocity. Horizontal wind components are inferred from the measurements of the oblique and vertical beams under the assumption of horizontal wind local homogeneity. Finally, vertical profiles of the three wind components, and for each beam spectral width and radar reflectivity are obtained every $5 \mathrm{~min}$. A more detailed technical description can be found in Jacoby-Koaly et al. (2002). The quality assessment of the UHF profiler measurements was validated during a 1-year campaign with the use of rawinsoundings, sodar and sonic anemometers (Dessens et al., 1997). The ability of UHF radar to detect rain with even a weak intensity was used in comparison to the droplet size distributions observed by a disdrometer at the ground level, allowing the instruments' reflectivity to be calibrated and to assess the vertical velocity and spectral width retrieval (Campistron et al., 1997).

\subsubsection{Sodar wind profiler}

The third remote-sensing device used here is the Doppler sodar manufactured by the Metek Company. This instrument operated continuously at the Vallon Dol site with a $2200 \mathrm{~Hz}$ transmitted central frequency. This acoustic sounding provided the horizontal components of the wind and spectral width from $320 \mathrm{~m}$ up to $750 \mathrm{~m}$ a.s.l. (depending on the atmospheric conditions) by $25 \mathrm{~m}$ vertical steps and a $15 \mathrm{~min}$ average time.

\section{Local meteorological conditions}

The set of meteorological ground stations provides a temporal analysis of the wind and temperature over Marseille and the suburbs. The complex topography of the region induces several breezes which compete over the city. The wind vertical profile is available over Marseille's centre and over the northern suburb, thanks to the sodar and the UHF instruments.

\subsection{Meteorological ground stations}

The second day, 25 June, of the photochemically polluted IOP $2 b$, was characterized by a ridge of high pressure extending from Maghreb to the Northern Sea. The surface pressure gradient was weak, leading to a weak synoptic northern wind flow. These conditions are in favour of the development of local meteorological phenomena (like a sea breeze and slope effects) and pollution events.

Horizontal wind direction and wind speed from the various ground stations (Fig. 2) suggest an interaction between two main sea breezes flowing from the western and the southern coasts, as already observed on 26 June (Delbarre et al., 2005). In the morning (from 08:45 UTC), one may note the development of local sea breezes, whose direction varies according to the nearest coast line position. Thus, the ground stations located at Marseille are under the influence of a westerly sea breeze (direction varies from 230 up to $300^{\circ}$ ), whereas the Cassis ground station, near the southern coast, measured a southerly sea breeze. In the afternoon (from 14:00 UTC), the 

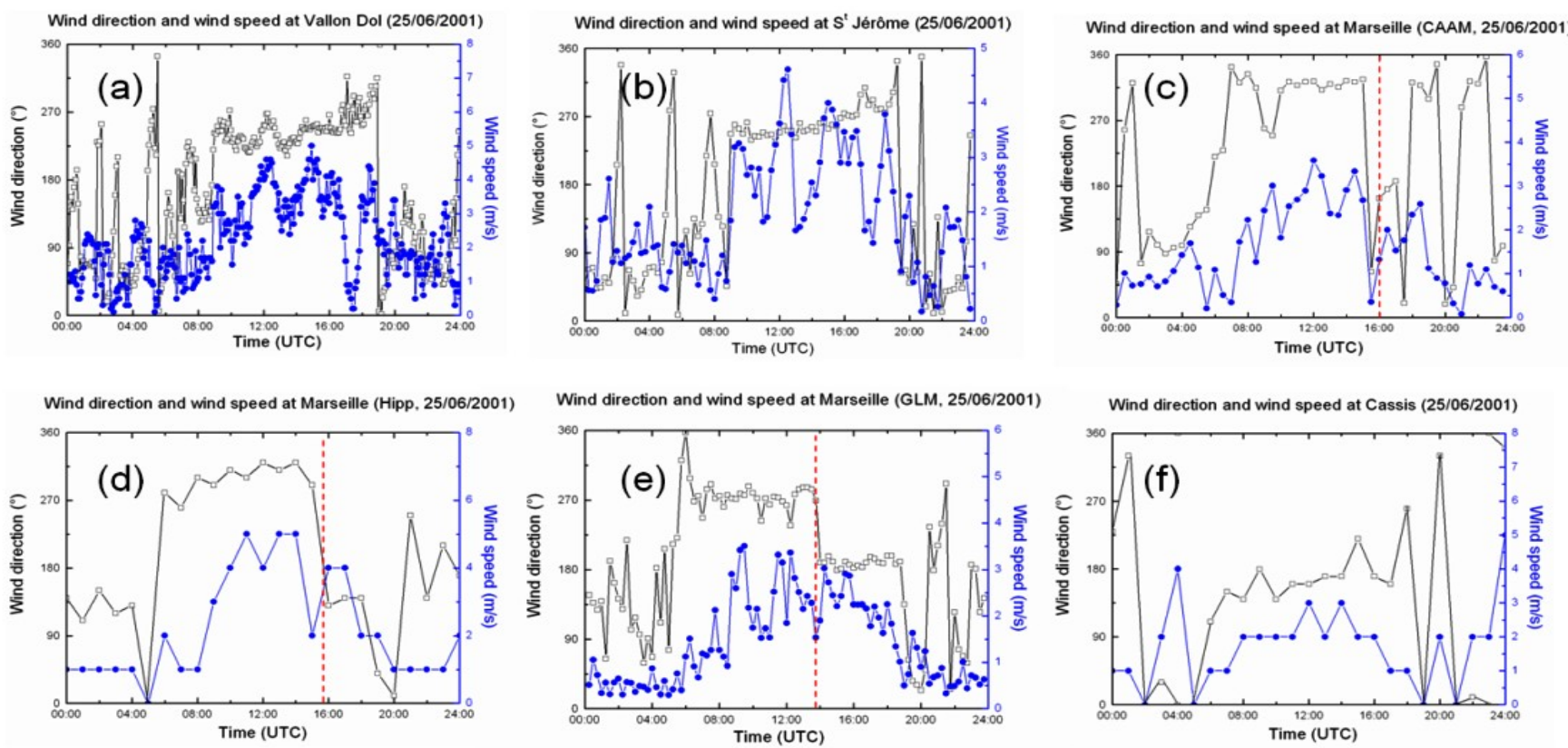

Fig. 2. Horizontal wind speed (filled circles) and direction (squares) from surface meteorological stations on 25 June: (a) Vallon Dol, (b) St Jérôme, (c) CAMM, (d) Hipp, (e) GLM, (f) Cassis (dashed lines represent the southerly sea breeze onset).
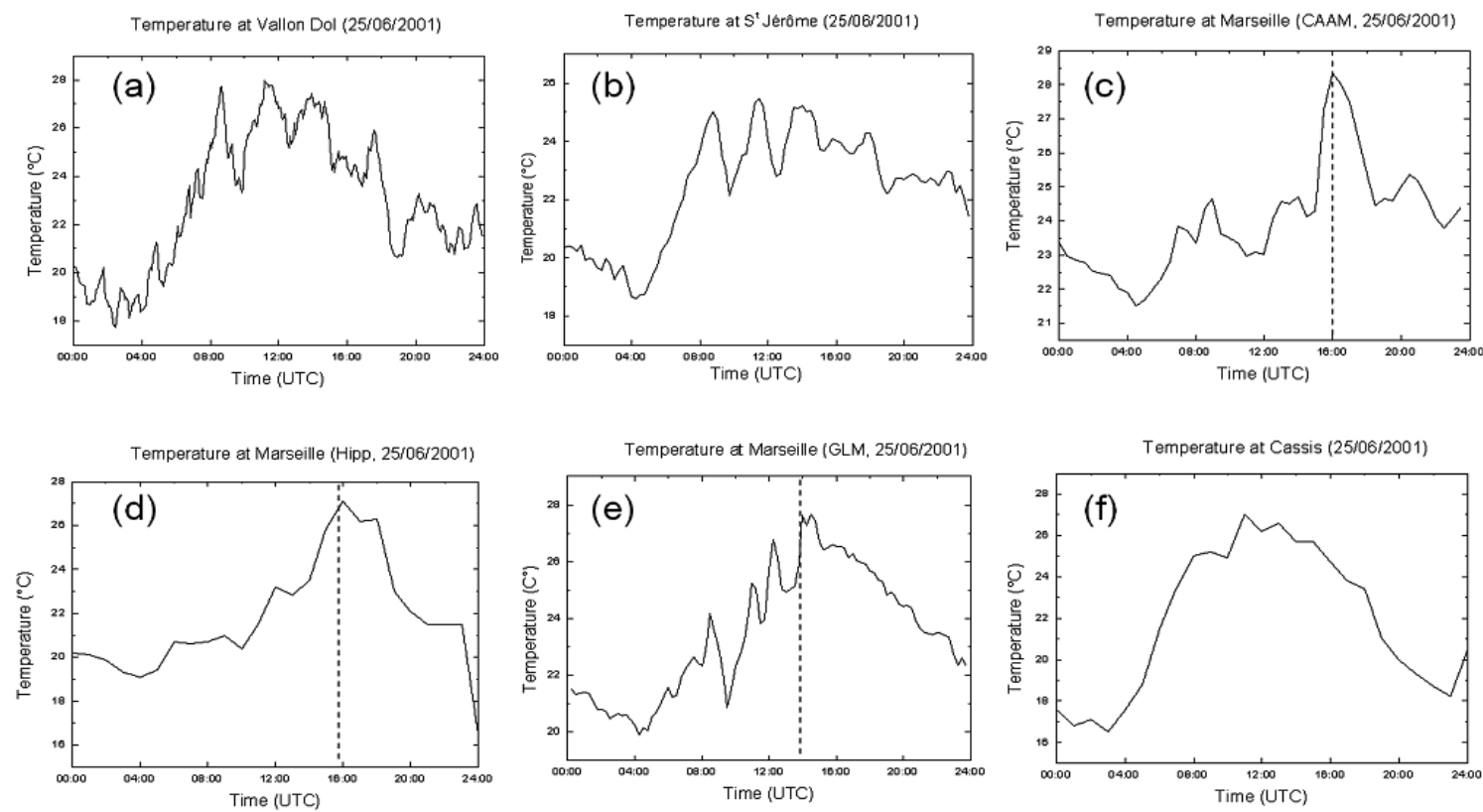

Fig. 3. Same as Fig. 2 for temperature measurements.

southerly sea breeze (S sea breeze) extends from the south of Marseille up to the town centre.

According to their local meteorological behaviour, ground meteorological stations may be classified within four cases in the Marseille and suburbs area:

- Northern suburb: a persistent westerly sea breeze. After its setting at 09:00 UTC, indicated by a wind direc- tion change, the westerly sea breeze (W sea breeze) persists the whole day long in the northern suburb at Vallon Dol and St Jérôme (Fig. 2, diagrams a, b). Let us note the wind direction and wind speed oscillation (Puygrenier et al., 2005) during the sea breeze period between 08:45 UTC and 20:00 UTC. 

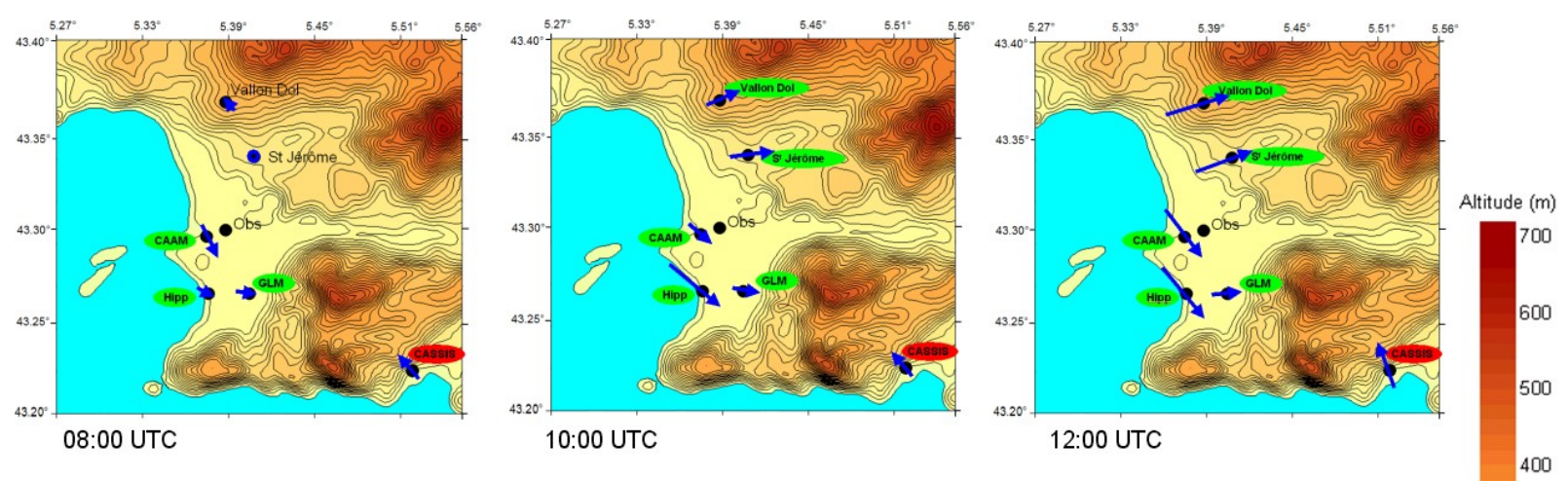

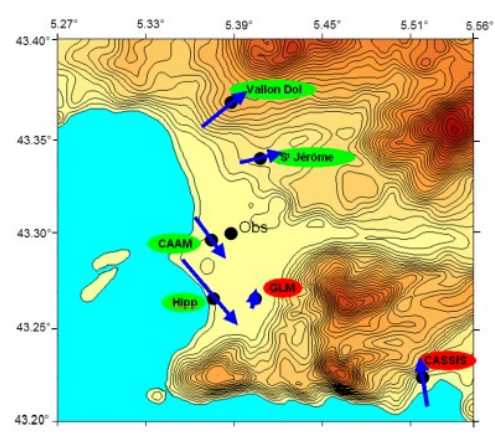

14:00 UTC

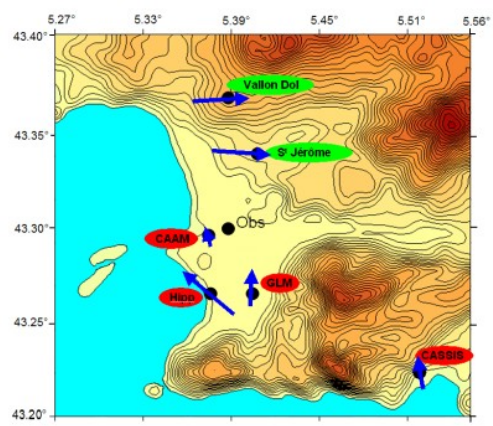

16:00 UTC

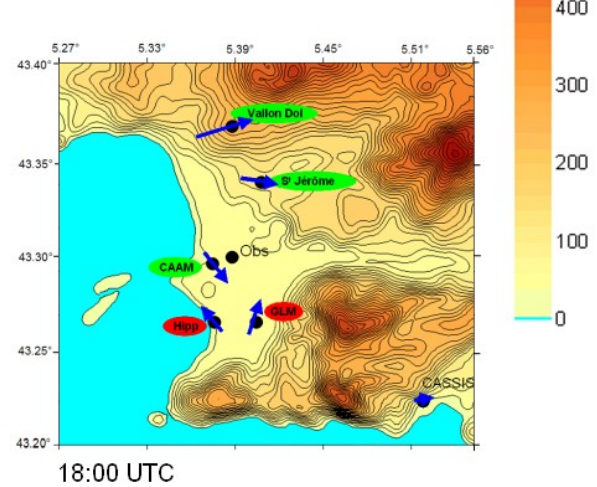

Southern sea breeze

Western sea breeze

$5 \mathrm{~m} / \mathrm{s}$

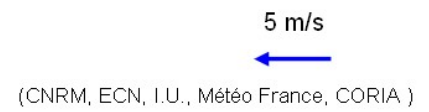

Fig. 4. A representation of competing westerly and southerly sea breezes according to ground station measurements on 25 June.

- Downtown: westerly and southerly breeze alternation. Two main sea breezes may be observed downtown at CAAM. Between 07:00 and 15:00 UTC, the W sea breeze prevails and is followed by an alternation of $\mathrm{S}$ and $\mathrm{W}$ sea breezes.

- Southern suburb: westerly sea breeze in the morning and southerly in the afternoon. This case consists, on the one hand, of a W sea breeze occurring in the morning at Hipp and at GLM, for instance, and on the other hand, of a S sea breeze setting during the afternoon. The W sea breeze starts early in the morning at 07:00 UTC at Hipp and 08:30 UTC at GLM. From 13:30 UTC at GLM and from 15:00 UTC at Hipp, the W sea breeze stops and is then replaced by a S sea breeze. This one reaches GLM first, probably because of the Calanques ridge located in the south of Marseille and the interaction with the $\mathrm{W}$ sea breeze. The proximity of the western coast and the Marseille-Veyre (Fig. 1) mountain leads to a delay of the $\mathrm{S}$ sea breeze starting at Hipp.

- South coast: south sea breeze the whole day long. A S sea breeze prevails the whole day long, as seen at Cassis on the south coast (Fig. 2, diagrams f). The $\mathrm{S}$ sea breeze starts at 08:00 UTC and ends at 18:00 UTC.
Figure 3 presents the diurnal evolution of the surface temperature for the six ground stations. All these curves are very different. Except in Cassis, where the temperature presents a classical symmetrical shape centred at noon, the other temperatures sometimes oscillate, as in Vallon Dol, St. Jérome and Marseille GLM, or sometimes have abrupt changes, as in CAAM and Hipp. The air temperature depends on the transit duration of the advected cool marine air above the continental surface. The longer transits result in the higher temperature. The transit duration value is defined by the wind speed and the distance to the coastline in the wind direction. The diurnal evolution of the temperature reflects the complex dynamical situation described above and is characterized by the multiple breezes. As the dynamical situation changes in both time and space and control the temperature variation, only the Cassis site has a stabilized $2 \mathrm{~ms}^{-1} \mathrm{~S}$ sea breeze, implying a classical diurnal temperature evolution.

Figure 4 summarizes the nature of the local sea breeze over Marseille described previously. The interaction between the two main sea-breeze flows coming from the western or southern coasts has been observed. In the morning (from 08:00 UTC), weak thermal gradients induce local weak sea breezes in a direction roughly perpendicular to the local coastline. Hence, the W sea breeze is well developed on the western coast and in the north of Marseille, and the S sea 


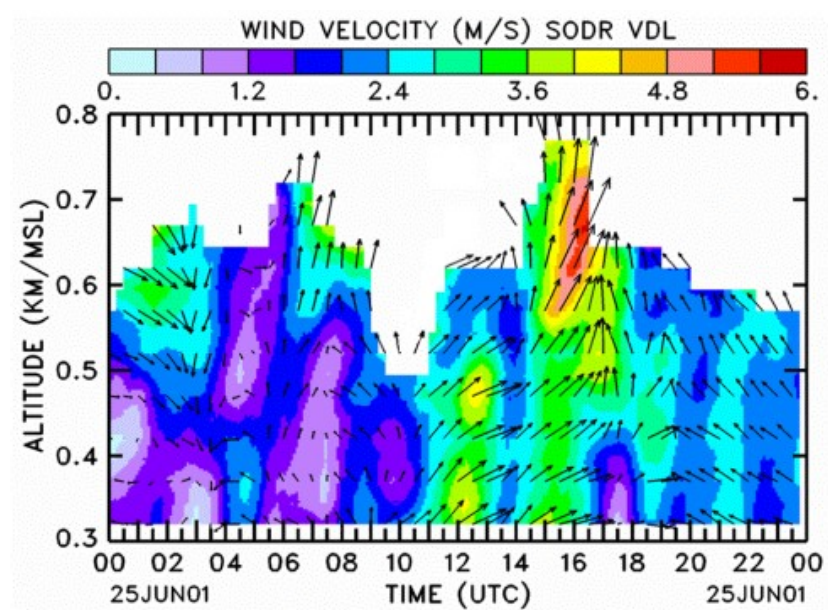

Fig. 5. SODAR measurements at Vallon Dol: Horizontal wind on 25 June.

breeze only develops near the southern coast. During the afternoon (from 14:00 UTC), as the thermal gradient increases with solar heating, the sea breeze can attain higher speed to reach a mesoscale dimension. Due to the east-west orientation of the mesoscale coastline, a S sea-breeze competes with the local W sea breeze and tends to grow from the south coast to the north. Ground stations effectively show that the thermal gradient allows the $\mathrm{S}$ sea-breeze to reach the town centre.

3.2 Vertical wind profiles from sodar and radar measurements

The Doppler sodar, located at Vallon Dol in Marseille's northern suburbs, detected the south-westerly sea-breeze flow from 09:00 UTC to 19:00 UTC, with maximum horizontal velocities (3.5 to $4 \mathrm{~ms}^{-1}$ ) at about 12:00 and 16:00 UTC (Fig. 5). This local sea-breeze flow is overlaid by a southerly flow with the highest wind velocity (4 to $6.4 \mathrm{~ms}^{-1}$ ) around $600-700 \mathrm{~m}$ a.s.l. at about 16:00 UTC. After this W sea-breeze period, the land breeze from the south-east returns. As illustrated by the radar measurements in Fig. 6, the dynamic situation at Obs is much more complicated than at Vallon Dol, since competition between local and mesoscale breezes occur in the city centre. In agreement with the surface station located at CAAM, the UHF profiler detects a westerly local breeze setting at 09:00 UTC. This is confined under a $350 \mathrm{~m}$ high with a southerly flow above. The dynamic situation evolves rapidly since the westerly breeze layer becomes thinner and is no longer detected from 11:00 UTC above the $200 \mathrm{~m}$ height. The mesoscale southerly breeze, which is settled in altitude between $200 \mathrm{~m}$ and $700 \mathrm{~m}$ at 11:00 UTC, extends in the afternoon up to $1300 \mathrm{~m}$. It is useful to note that the southerly sea breeze reaches the surface only once in the afternoon between 15:30 and 17:30 UTC (Fig. 2c). Consequently, the competition be-

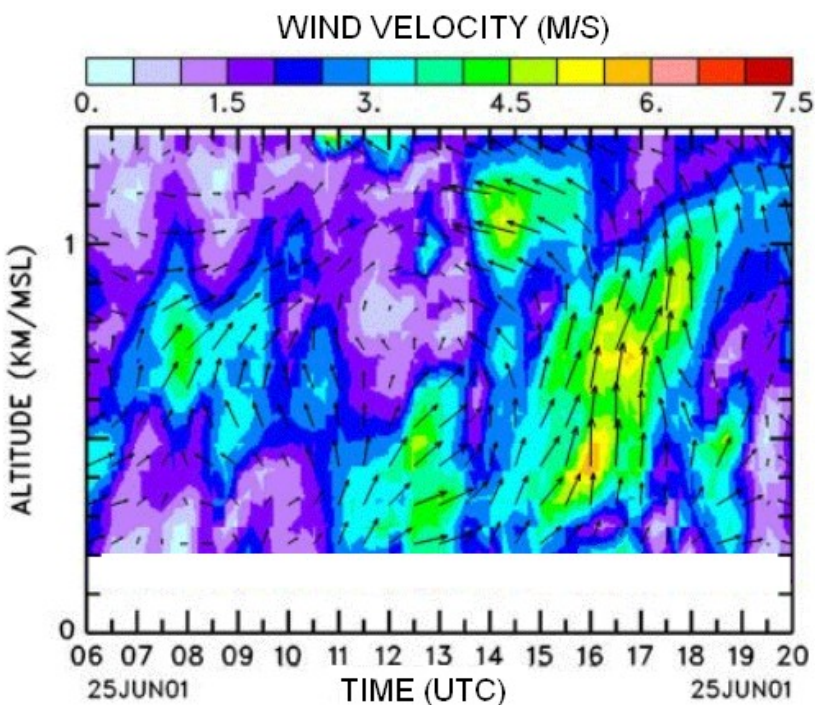

Fig. 6. UHF RADAR measurements at Obs.: horizontal wind timeheight cross section measured on 25 June (horizontal vectors wind measured by the profiler are superimposed).

tween the two breezes can be seen both in the vertical dimension of the atmospheric column and in the breeze diurnal temporal variation. As it has been observed on 26 June 2001, a E-S-E flow is detected above $800 \mathrm{~m}$ a.s.l., between 14:00 and 16:00 UTC.

\section{Lower troposphere stratification and dynamics above Marseille's area}

The UV lidar and the UHF radar were located in Marseille's northern suburb and downtown, respectively. They give the opportunity to investigate the lower troposphere stratification over two places, whose dynamical characteristics are very different. This stratification is analysed in light of the wind vertical profile already discussed.

\subsection{Stratification above Vallon Dol by UV lidar measure- ments}

Lidar measurements from 05:30 UTC until 19:30 UTC consist of a continuous succession of vertical scans of ozone and extinction (except for maintenance between 13:30 and 14:30). A convenient way for obtaining insight into the whole day dynamics is to build time-height maps by a vertical projection and to smooth the extinction or the ozone concentration determined along individual beams. The background of Fig. 7 displays such a time-height map for the extinction, where the extinction vertical distribution reveals that the lower troposphere is structured in several evolving layers. The fine structure of the lower troposphere is then determined by analysing the individual backscattering signals with the inflexion point method, in order to determine precisely the 


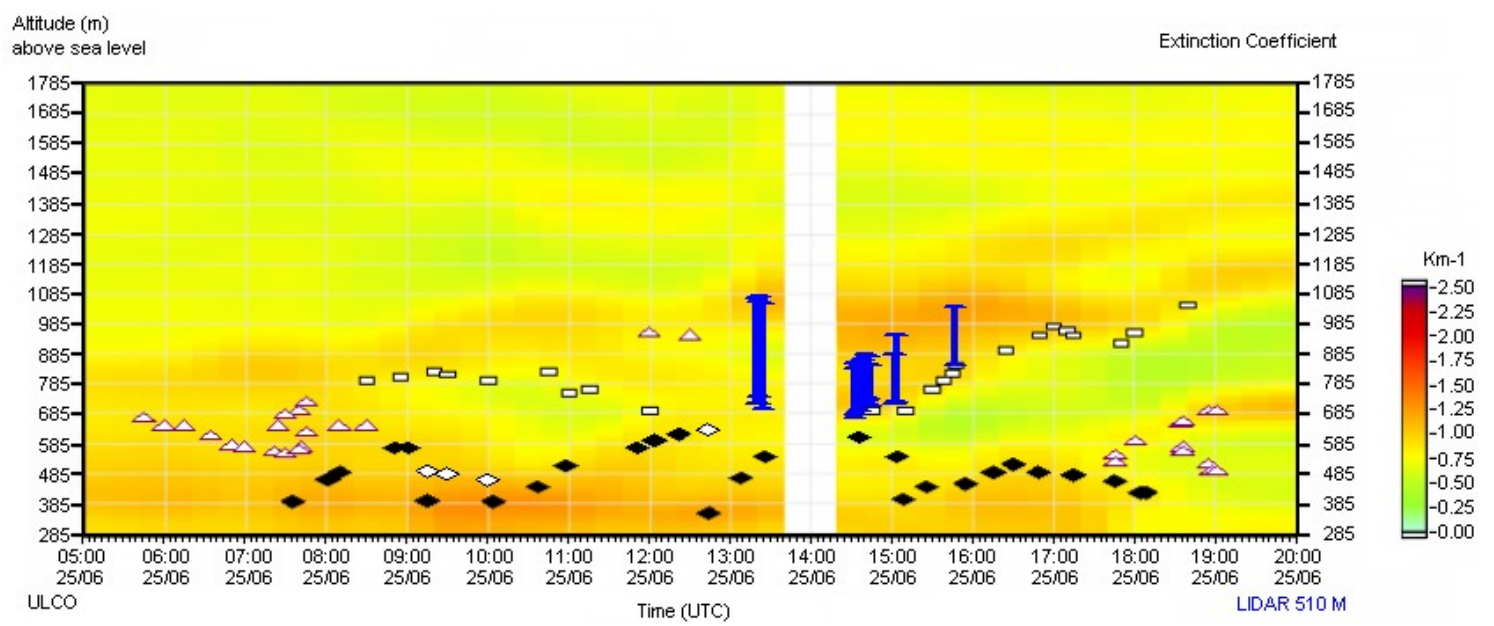

Fig. 7. Time-height section of extinction coefficient derived from the UV lidar made on 25 June 2001. Stratification transitions (determined by IPM) are superimposed on the extinction map: lower layer top (black diamonds), residual layer top (white diamonds), middle layer top (rectangles), interface layer (blue bars) and fine layer (triangles).

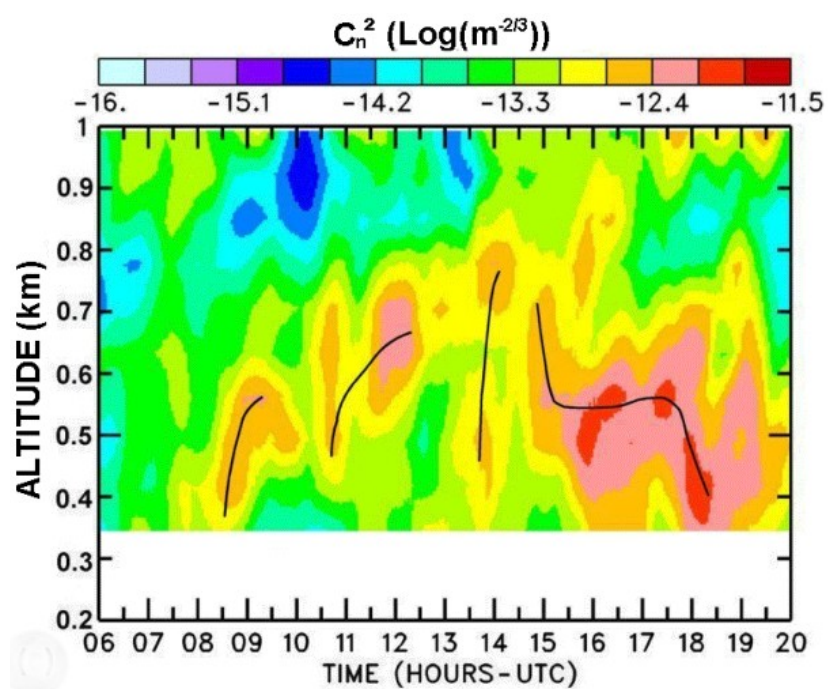

Fig. 8. Time-height section of radar reflectivity in terms of the structure function parameter for index of refraction $\left(C_{n}^{2}\right)$ derived from UHF profiler observations made on 25 June 2001 (superimposed black curve indicate $\mathrm{C}_{n}^{2}$ maxima).

layer transitions. The detected layer transitions are superimposed on the extinction time-height maps in Fig. 7.

The extracted fine structure shows that the lower troposphere has numerous superimposed layers which evolve during the day. From 09:00 UTC, after the W sea-breeze setting up to 12:00 UTC, the lower troposphere may be divided into at least three layers. This triple layer scheme is composed of a lower layer with a high extinction $\left(1-1.8 \mathrm{~km}^{-1}\right)$, whose top is located by black diamonds (see Fig. 7). This lower layer is surmounted by a middle layer with lower extinction $\left(<0.7 \mathrm{~km}^{-1}\right.$ between 08:00 and 12:00 UTC) enclosed by black diamonds and white rectangles. This middle layer is surmounted by an upper layer above $800 \mathrm{~m}$ a.s.l. The three layer scheme may be recognized in the afternoon, after 16:00 UTC. However, from 13:00 up to 16:00 UTC, the stratification becomes more complex, due to an optically heterogeneous zone embedded between homogeneous layers, which will be referred to as an interface layer. As this interface layer is heterogeneous and the slope method for extinction is not valid in this region, the corresponding region has been localized specifically with blue bars. During the interface layer occurrence, the middle layer is not easily visible but reappears as the interface layer vanishes (after 15:30).

\subsection{Stratification above Marseille by radar measurements}

The vertical stratification can also be studied using vertical profiles of the structure coefficient of the air refractive index $\left(C_{n}^{2}\right)$ measured by the UHF radar. High values of this parameter are located at the boundary layer top (Zi), where significant humidity gradients are associated with turbulence. The $\mathrm{C}_{n}^{2}$ vertical profiles allow a temporal examination of the boundary layer depth. Over a continental surface, the convective boundary layer depth steadily increases and its top is defined by a continuous line of $\mathrm{C}_{n}^{2}$ maxima. In the present case (see Fig. 8), $\mathrm{Zi}$ increases discontinuously from $400 \mathrm{~m}$ at $08: 30$ up to $750 \mathrm{~m}$ at $14: 30$ UTC, since three successive $\mathrm{C}_{n}^{2}$ maxima can be observed at 08:30-09:30, 11:00-12:30 and 13:30-14:30 UTC. Between these maxima, $C_{n}^{2}$ values decrease significantly. 

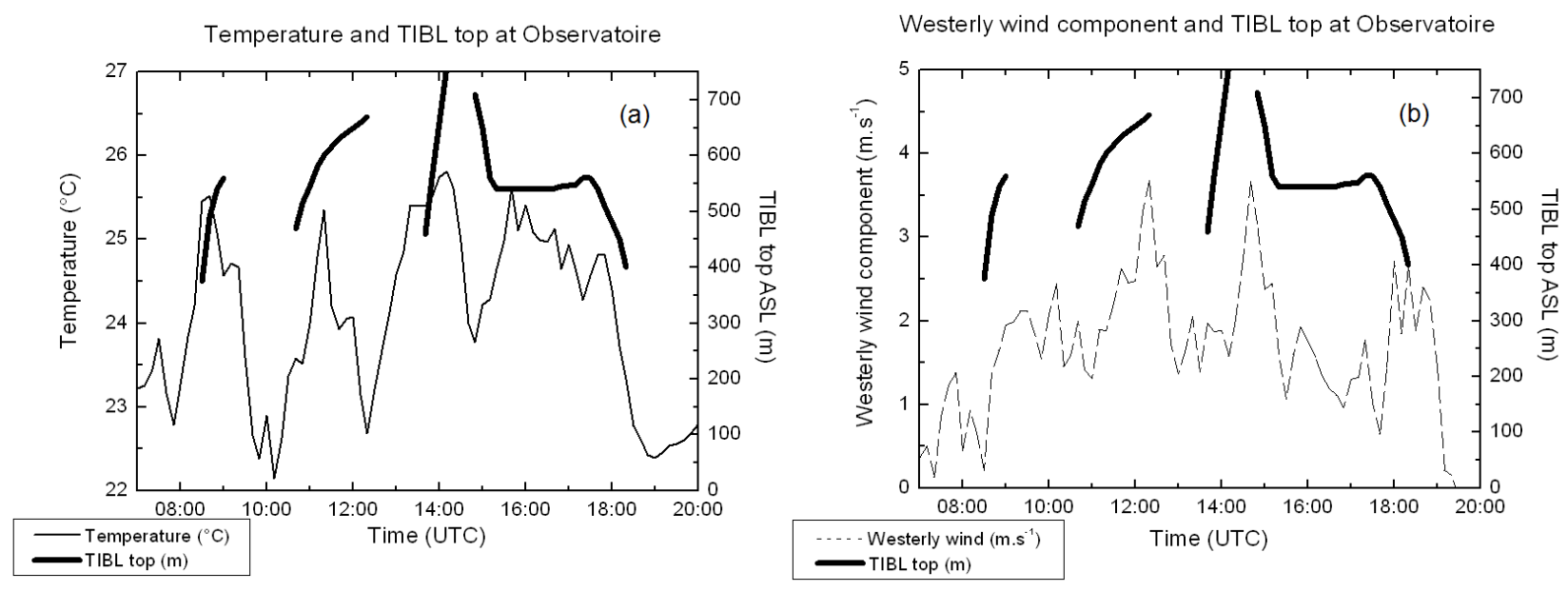

Fig. 9. (a) Temperature and (b) westerly wind component measured at the surface at Obs and TIBL top from UHF profiler on 25 June.

\subsection{Layers dynamics discussion}

\subsubsection{Thermal internal boundary layer}

Interpretation of the UV lidar signals shows that the lowest layer (below $600 \mathrm{~m}$ a.s.l.) is characterized by a repetitive height increase followed by a discontinuity. The ABL displayed on Fig. 7 develops up to $600 \mathrm{~m}$ at 09:00 UTC before the breeze. A first discontinuity occurring at 09:00 UTC corresponds to the Vallon Dol W sea-breeze development. The lower layer with high extinction $\left(1.8 \mathrm{~km}^{-1}\right)$ may then be identified as the thermal internal boundary layer (TIBL), which develops when the marine flow encounters the shoreline (Nazir et al., 2005). Let us note that a residual layer above (white diamonds) quickly disappears at about 10:00 UTC. The TIBL continuously thickens up to $600 \mathrm{~m}$ a.s.l. at about 12:00 UTC, when a second discontinuity occurs. A new TIBL develops at 12:30 UTC and thickens, etc. The scenario repeats twice: between 12:30 UTC and 15:00 UTC and more subtly between 15:00 UTC and 18:00 UTC (the Vallon Dol sea-breeze end). Hence, the TIBL evolution is observed both by UV lidar in Vallon Dol and UHF in Marseille's center (see Fig. 8). This particular behaviour of the boundary layer is the consequence of the sea-breeze intensity variations already described in detail in Puygrenier et al. (2005). In a sea-breeze system, the continental boundary layer depth depends on the transit duration of the marine air over the land surface. The longer the transit duration is, the thicker the continental boundary layer. On 25 June, the westerly wind component intensity has a periodic variation, as shown in Fig. 9. When the sea breeze is low, the temperature increases and the boundary layer depth rises. On the contrary, when the sea breeze intensity is high, the marine air has less time to homogenise its potential temperature profile and the boundary depth can be very low.
As observed at Obs, the surface temperature and the TIBL top variations at Vallon Dol are also well correlated as shown in Fig. 10.

\subsubsection{Southerly sea-breeze flow evolution above the TIBL}

According to the sodar, the middle layer above the TIBL (Fig. 7) is a southerly flow which may be identified as the S sea-breeze flow coming above the $\mathrm{W}$ sea breeze flow by considering the sea-breeze crossing. This southerly flow is observed the whole day long, except during the interface layer occurrence. This layer is characterized by a low extinction but the backscattered signal is greater than the TIBL one.

\subsubsection{Interface layer}

Another layer, located above the S sea breeze, is detected by the UHF radar (Fig. 6) above $1300 \mathrm{~m}$ a.s.1. at 11:00 UTC and $900 \mathrm{~m}$ a.s.1. at 14:00 UTC. This layer is associated with an easterly flow. Extinction is low $\left(0.8 \mathrm{~km}^{-1}\right)$ in the morning but from 13:00 UTC to 16:00 UTC, the lidar detects a heterogeneous layer (interface layer) whose altitude increases with the S sea breeze top from 15:00 UTC.

\section{Main atmospheric dynamical features}

The ground-based meteorological stations over Marseille's domain, the northern measurements from the UV lidar and sodar, and the downtown radar have been investigated to bring up relevant low troposphere dynamical elements. Two main local phenomena govern the boundary layer. Crossed southerly and westerly sea breezes first compete the whole day long over the whole town. The westerly sea breeze perpendicular to the coastline dominates in the morning but the larger scale southerly sea breeze extends in the afternoon, pushing to the north and up to the town centre. 
Temperature and TIBL top at Vallon Dol (25/06/2001)

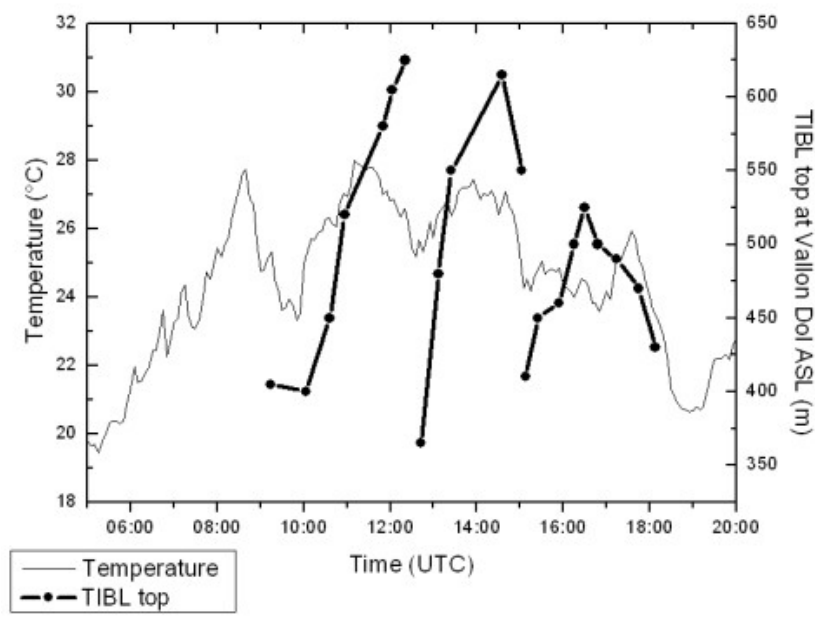

Fig. 10. Evolution of the TIBL top from UV lidar and temperature measurements at ground.

Secondly, the westerly sea-breeze pulsed nature complicates the dynamics. The interface layer occurrence is a third phenomenon of minor importance for the boundary layer. Both the sea-breeze confrontation and westerly sea-breeze pulsation phenomena influence the low layers' structure and dynamics, particularly the boundary layer. Schematically, the northern part of the town is dependent on the westerly sea breeze and the stratification results from a lower westerly flow, generally surmounted by a southerly sea-breeze flow (except during the interface layer occurrence). The pulsed nature of the westerly flow induces repetitive TIBL height variations. The town southern region is only under the southerly sea-breeze influence and the stratification is due to a southerly flow, which may be surmounted by an interface layer of easterly flow. The geographical limit between these crossed southerly and westerly sea breezes at ground level moves as the southerly sea breeze becomes stronger than the westerly sea-breeze flow. These features are signatures of atmospheric dynamics and their relationship with ozone and aerosols evolution will be investigated in the following section.

\section{Pollutants distribution under crossed and/or pulsed sea-breeze local phenomena}

6.1 Northern ozone vertical distribution and local phenomena crossed analysis

The UV lidar measurements provide a continuous vertical distribution monitoring of ozone, which is combined with the lidar stratification in Fig. 11. The ozone map is consistent with the previous extinction distribution (Fig. 7) and reveals the ozone features of the specific TIBL, S sea breeze and interface layer. High ozone concentration regions are mainly located within the W sea-breeze TIBL (120 to $230-\mu \mathrm{gm}^{-3}$ ), mixing the pollutants in a layer whose depth varies several times in the day. Is the TIBL ozone concentration related to the breeze pulsations? The TIBL ozone has been extracted from lidar measurements at a $325 \mathrm{~m}$ altitude, and is compared with the TIBL height deduced from lidar signals at Vallon Dol (Fig. 12).

Each TIBL discontinuity associated with a sea-breeze strengthening is systematically associated with an abrupt ozone decrease. During the ABL development before the breeze, the ozone had reached a $150 \mu \mathrm{gm}^{-3}$ concentration at 09:00 UTC. The W sea breeze setting is accompanied with an $60 \mu \mathrm{gm}^{-3}$ ozone decrease. The ozone concentration reaches $210 \mu \mathrm{gm}^{-3}$ (12:00 UTC) by following the TIBL thickening and abruptly decreases to about one-half of the concentration, whereas the solar radiation is strongest and would imply a photochemical production. This behaviour then repeats twice with a decreasing ozone concentration amplitude, however. Hence, the TIBL ozone clearly depends on the pulsed sea breeze advecting cold air from the western coast over Marseille's northern harbour. Moreover, dilution and production processes competition result in a TIBL ozone decrease during each breeze intensification. Finally, the above S seabreeze is distinguished from the $\mathrm{W}$ sea breeze by a weaker ozone concentration $\left(<120 \mu \mathrm{gm}^{-3}\right)$, whereas the interface layer carries more polluted air masses.

6.2 Downtown surface ozone distribution and local phenomena crossed analysis

The downtown area is alternatively subjected to the pulsed $\mathrm{W}$ sea breeze or the S sea breeze at ground level. We now investigate the role of these local phenomena on downtown ozone surface concentration.

Air quality network ground stations (AIRMARAIX) are located at St Marguerite south of town near GLM, at $5 \mathrm{Av}$ enues in the town centre near CAAM, and Obs. The St Marguerite ozone concentration level is about twice that of $5 \mathrm{Av}$ enues for the whole day long (see Fig. 13). Moreover, both ozone curves are quite similar, with 2 maxima in the afternoon. However, the timing is different although these stations are very close $(5 \mathrm{~km})$. Their maximum concentration is reached at about 16:00 UTC at St Marguerite and 18:00 UTC at 5 Avenues. The 5 Avenues ozone remains constant (09:0014:00 UTC) when the solar radiation is strongest. Wind comparisons explain these peculiarities.

The St Marguerite ozone concentration and GLM wind direction are displayed in Fig. 14. The W sea breeze dominates at GLM from 08:30 to 13:30 UTC, with a $100 \mu \mathrm{gm}^{-3}$ maximum ozone concentration before being replaced by the $\mathrm{S}$ sea breeze. The sea-breeze alternation is featured by a rapid $30 \mu \mathrm{gm}^{-3}$ ozone jump and a relatively strong concentration remaining along the S sea breeze (14:00-19:00 UTC). A new ozone collapse occurs when the $\mathrm{S}$ sea breeze ends 


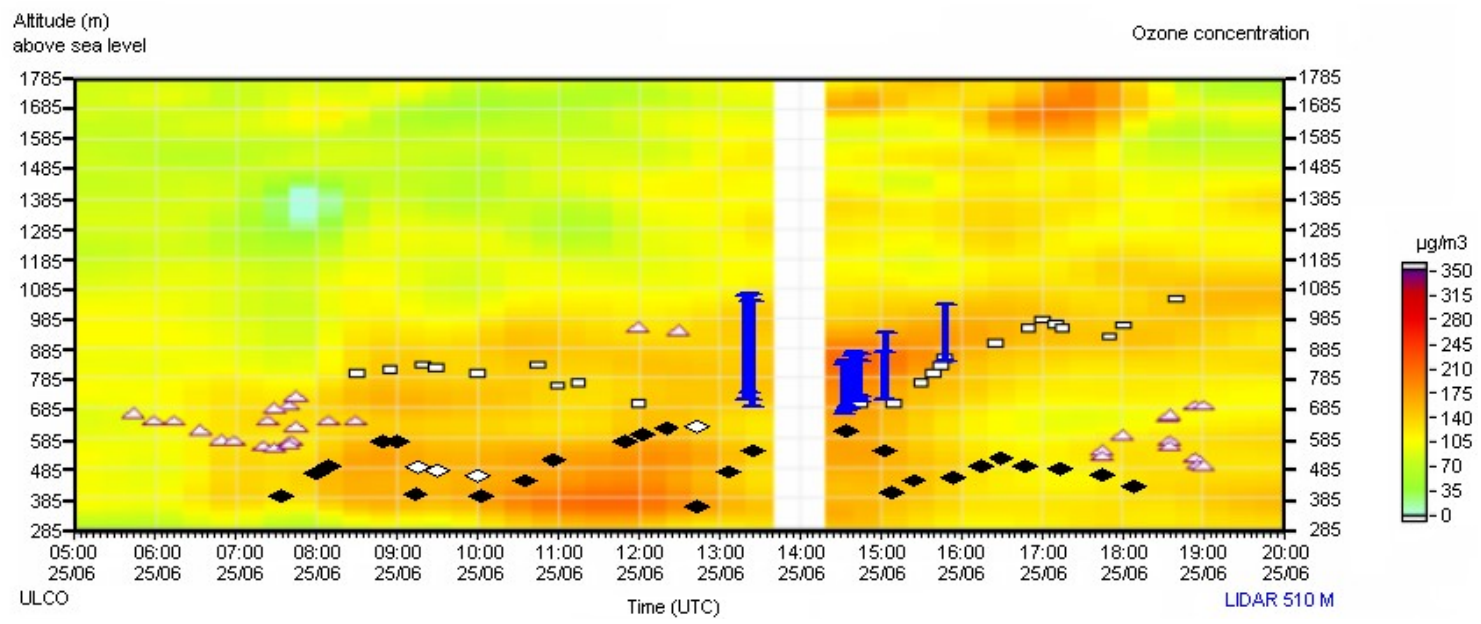

Fig. 11. Ozone concentration time-height map from UV lidar measurements on 25 June 2001, superimposed with lidar stratification. ABL top (black diamonds: before 09:00 UTC), thermal internal boundary layer top (black diamonds: after 09:00 UTC), residual layer top (white diamonds), S sea breeze top (rectangles), interface layer (blue bars) and fine layer (triangles).

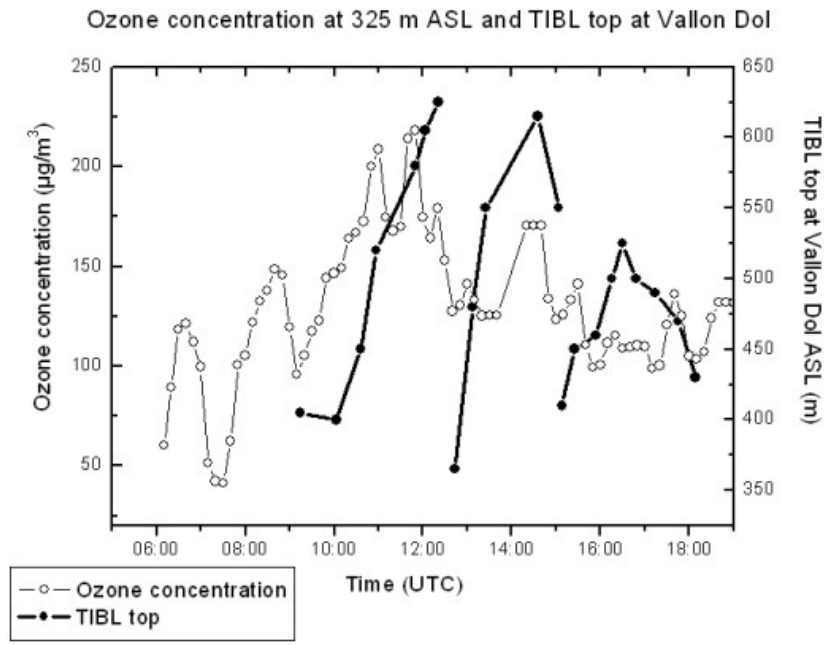

Fig. 12. Comparison of the TIBL top and ozone concentration from UV lidar.

(19:00 UTC). The alternation of W and S breezes occurs later at 5 Avenues (about 15:30 UTC), with a shorter S sea-breeze period (Fig. 15) which is also associated with an increase in ozone concentration. The correlation between ozone and local events does not explain the relative ozone levels which depend on many other regional factors. The ozone horizontal distribution is strongly related to the horizontal extent and dynamics of the local events. Finally, let us note that the poor hourly ozone resolution does not allow us to observe the consequences of a rapid pulsed breeze.

The $\mathrm{W}$ pulsed sea breeze may be analysed using the surface ozone concentration measured at 5 Avenues with a better resolution (15 min). The ozone is compared to the TIBL
Ozone concentration measurements from Airmaraix surface stations

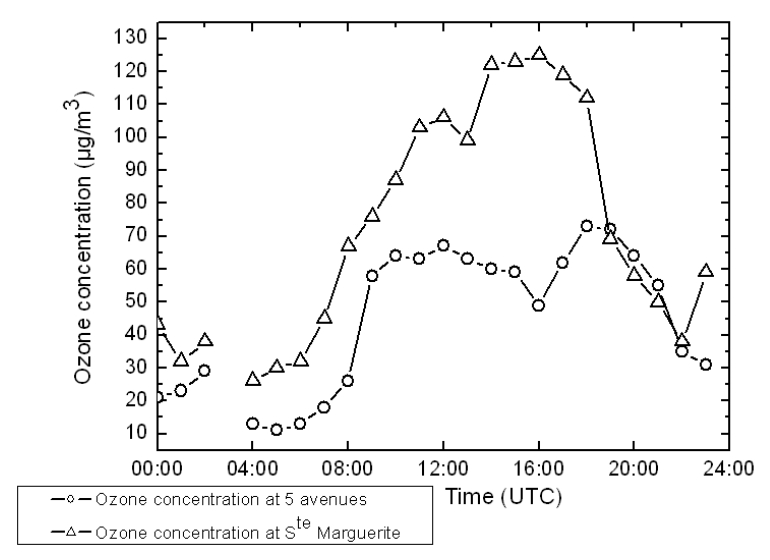

Fig. 13. Hourly ozone concentrations from AIRMARAIX air quality network at 5 Avenues and at St Marguerite.

top fluctuations deduced from UHF data, shown in Fig. 16. Although the similar comparison for the Vallon Dol site (Fig. 12) showed correlated oscillations of the ozone concentrations and the TIBL top, the situation downtown does not exhibit such a simple relationship. Ozone pollution classically rises during the morning to $70 \mu \mathrm{gm}^{-3}$ at about 09:00 UTC. Three important decreases down to $40 \mu \mathrm{gm}^{-3}$ can then be observed during the $\mathrm{W}$ sea-breeze period: at 10:00, 12:00 and 14:00 UTC at Obs. The first one coincides with the first collapse of the TIBL top and other decreases happen when the sea-breeze intensity is low and the TIBL top is high. The relationship between ozone and TIBL is, however, quite different than that observed at Vallon Dol, and the correlation is less clear downtown than in the suburbs (Puygrenier et al., 2005). The pulsed sea breeze seems to have a 


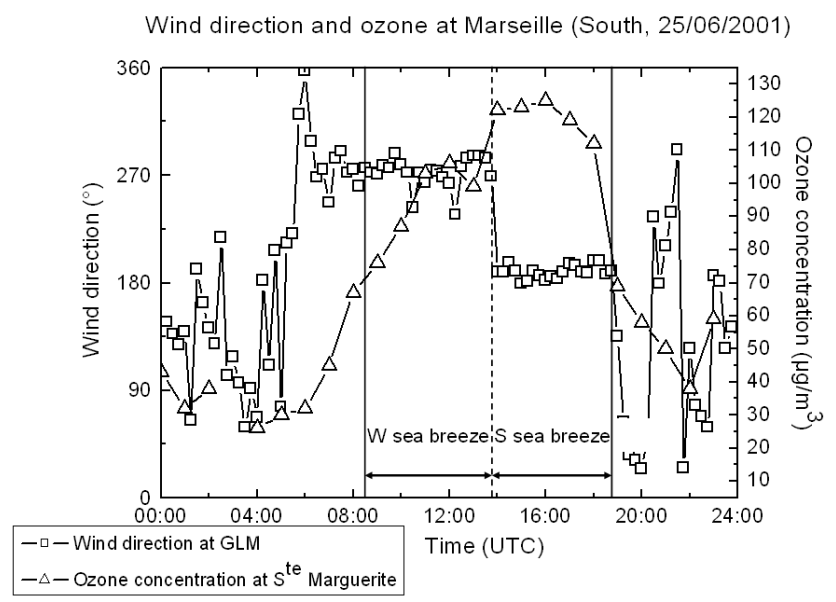

Fig. 14. Hourly ozone concentration from AIRMARAIX air quality network at St Marguerite and wind direction at GLM.

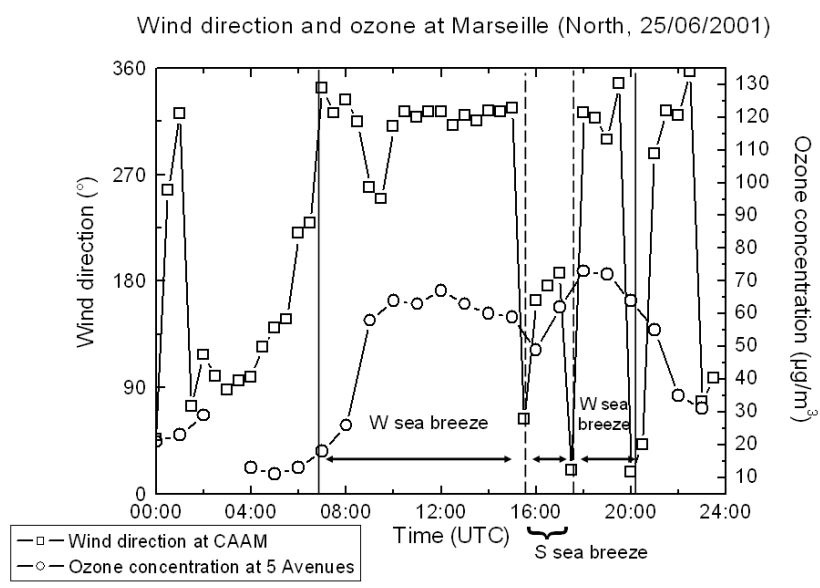

Fig. 15. Hourly ozone concentration from AIRMARAIX air quality network at 5 Avenues and wind direction at CAAM.

different impact on the ozone concentration depending on the locations of the measurement sites. The breeze fluctuations are a determining factor of the transit duration of the marine air mass above the continental surface and consequently, of the pollution within. The pollution air loading downtown is obviously quite different from that in the suburbs of Vallon Dol. Ozone is a secondary product and the chemical reactions occur during transit from source regions.

\subsection{Downtown aerosols and local phenomena analysis}

Aerosol measurements were performed downtown and may help to define the potential consequences of pulsed seabreezes on atmospheric pollutant concentrations. The pulsed nature of the $\mathrm{W}$ sea breeze indeed determines the transit time of the marine air above the town and hence the convection and turbulent characteristics of the low level layers (Puygrenier et al., 2005). These features should influence

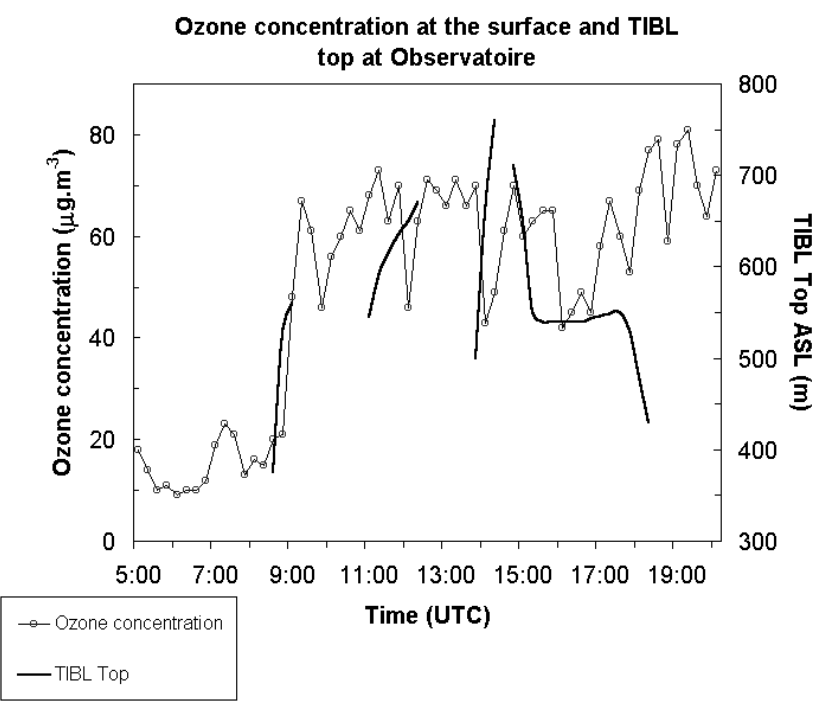

Fig. 16. Comparison of the TIBL top from UHF profiler at Obs and ozone concentration at the surface at 5 Avenues with a 15-min resolution.

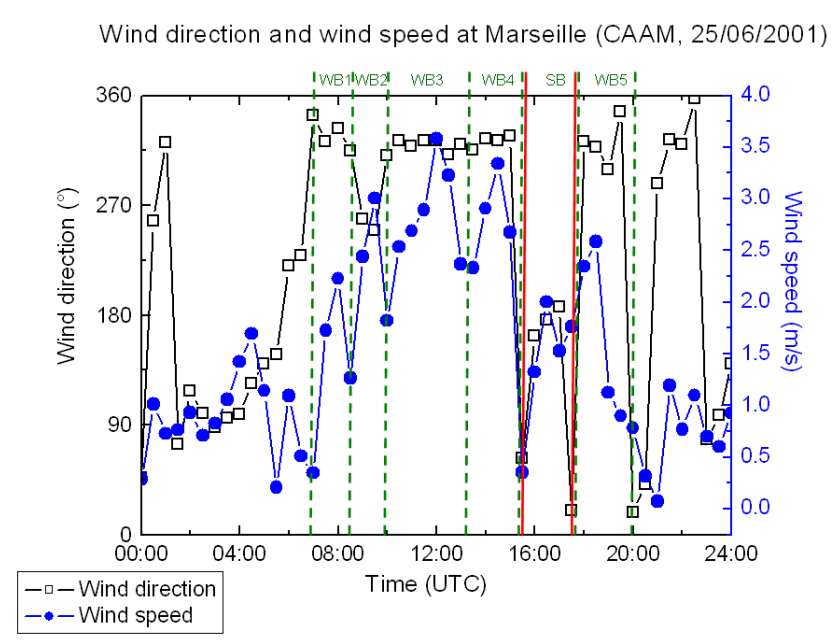

Fig. 17. Meteorological dynamical events during the sea-breeze period delimited by green vertical dashed lines for the $\mathrm{W}$ sea-breeze period and red lines for the $S$ sea-breeze setting.

the aerosol distributions and transformations in this complex coastal terrain within dense urban area traffic. In order to relate the aerosol concentrations and the pulsed breeze stages, the downtown sea-breeze period (CAAM) has been first separated into dynamical events, in order to locate precisely the breeze pulsations. These dynamical events are superimposed on Fig. 17 with the CAAM wind speed and wind direction. Each dynamical event is featured by a wind speed reinforcement and/or a wind direction change. This method leads to a classification of five pulsed W sea-breeze events, called WB1 to WB5 and one $\mathrm{S}$ sea-breeze called SB, which interrupts the WB4 sea breeze for a short period. 
The event classification may then be superimposed on the CAAM total aerosol concentration for comparison (see Fig. 18). The maximum aerosol concentration (about $12000 \mathrm{~cm}^{-3}$ ) is reached in the morning between 05:00 and 08:00 UTC. These high aerosol concentrations may be explained by intense traffic emissions during the morning rush hour and by the weak dilution in a thin TIBL. One may note a short concentration decrease at 07:00 UTC when the W sea breeze settled. WB2 is characterised by a lower aerosol concentration, which may be attributed to a wind direction change and an aerosol source anisotropy, and/or to the lowering of morning traffic emissions and finally, an increase in wind speed. Contrarily to the first WB1 and WB2 pulsed breezes, where the relation with aerosol concentrations is not obvious, the aerosol concentration correlates with the wind speed variation during WB3 and WB4. Each WB3 or WB4 period is associated first with a wind reinforcement and a low TIBL, which could limit the vertical dilution, and secondly with a wind speed decrease favouring a TIBL vertical development and then dilution. During each event, aerosols result from a competition between aerosol emissions, photochemical production and progressively increasing dilution. During WB3, this competition first leads to a strong aerosol concentration lowering progressively during the event. The WB4 period is interrupted by the $\mathrm{S}$ sea breeze. The $\mathrm{S}$ sea breeze period is mainly characterised by a weak and constant aerosol concentration. We expect, on the one hand, that the southern pollution has been efficiently and continuously transported to the north, inside the S sea-breeze layer, and on the other hand, that the emissions and production are lower in the late afternoon.

\section{Conclusion}

A photochemical pollution event in Marseille has been studied with remote sensing and ground-based measurements within the framework of the French ESCOMPTE campaign. The ozone UV lidar, the radar, the sodar and ground meteorological stations are complementary tools to investigate the relevant meteorological mechanisms for understanding the lower troposphere (and hence boundary layer) behaviour and the pollutant transport in a particularly complex region. The geographical features, particularly the irregular coastline orientation and the surrounding relief, result indeed in an intricate competition of local sea breezes along the coastline with a larger scale sea breeze, complicated by a pulsed sea-breeze phenomenon. Both phenomena determine the structure and the dynamics of the 3-D wind field and layer superpositions in the Marseille region. The horizontal extent of each breeze and their vertical structure of layers depend on the relative strength of local and larger scale sea breezes. The pulse sea breeze generates a boundary layer height oscillation. The ozone and aerosols under such an intricated meteorological dynamics have also been investigated with lidar and ground-

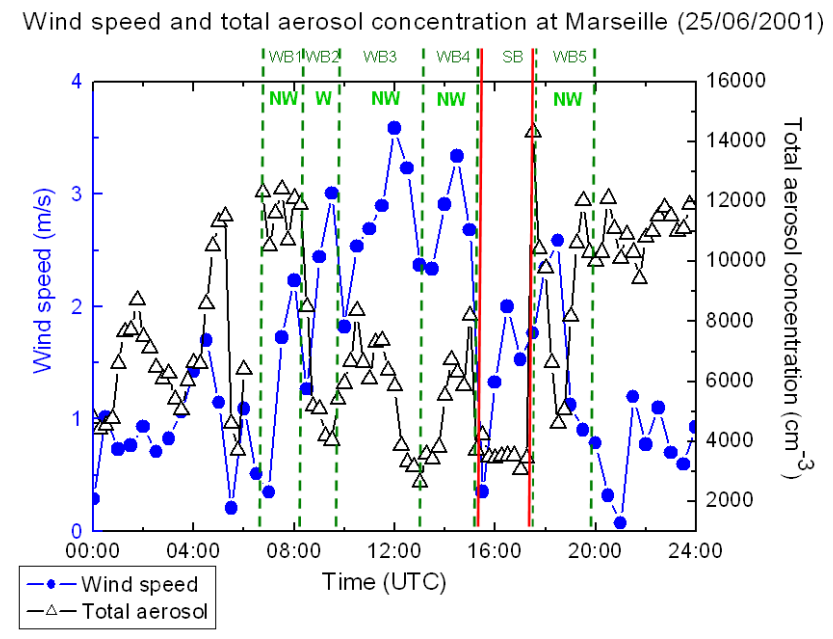

Fig. 18. Wind speed and meteorological dynamical events during the sea breeze period delimited by green vertical dashed lines for W sea breeze period and red lines for $\mathrm{S}$ sea breeze installation and total aerosol concentration (obtained from the LEPI laboratory in charge of measurements).

based measurements. We have shown that the pollutants' behaviour is clearly linked to the local meteorological events. Since the ozone concentration is related to the air mass transit time above town, both pulse and competing breezes contribute to the horizontal ozone heterogeneity. In the town periphery, pulse sea breezes result in a large amplitude oscillating ozone concentration within a TIBL, whose thickness evolves periodically. But this effect cannot be clearly observed downtown, showing that the understanding of the whole dynamics really needs to consider sources and chemistry along air mass trajectory. The pulse and competing seabreezes are also shown to take part in the downtown aerosols evolution. Similar analyses could be applied to other large towns with complex topography and photochemical pollution. Pollution understanding needs to consider the local meteorological events, and the local prediction models need to combine high resolution and chemistry.

Acknowledgements. We thank all the engineers, technicians and scientists who contributed to the success of ESCOMPTE as well as B. Cros and P. Durand who organized the campaign. We thank P. Mestayer (LMF, CNRS/ECN) for the coordination of the UBL side project. We also thank the numerous organizations involved in the ESCOMPTE financial support: the French Ministries of Research, National Development, and Environment, the Centre National de Recherche Scientifique/Institut National des Sciences de l'Univers (CNRS/INSU), the Agence De l'Environnement et de la Maîtrise de l'Energie (ADEME), Météo-France, the Centre National d'Etudes Spatiales (CNES) and the Comité de Coordination Régional (CCR) of the air quality watch networks of the ProvenceCôte d'Azur region.

The UV lidar was managed by the LPCA (UMR CNRS 8101) in cooperation with INERIS (Verneuil en Halatte. France). The UHF 
radar from CNRM was managed by the Laboratoire d'Aérologie (UMR 5560). Sodar measurements acquisition and treatment were carried out by A. Mériaux (Alliance Technologies), H. J. Kirtzel (Metek company) in cooperation with J. M. Rosant (Laboratoire de Mécanique des Fluides (LMF), CNRS/Ecole Centrale de Nantes $(\mathrm{ECN})$ ). We thank the AIRMARAIX monitoring network, ECN, CORIA, Indiana University, LEPI for providing the ozone, aérosols and meteorological data. We also thank our native English F. Hindle.

Topical Editor F. D'Andrea thanks two referees for their help in evaluating this paper.

\section{References}

Angevine, W. M., Trainer, M., McKeen, S. A., and Berkowitz, C. M.: Mesoscale meteorology of the New England coast, Gulf of Maine, Nova Scotia: Overview, J. Geophys. Res., 101, 28-893, 1996.

Bastin, S. and Drobinski, P.: Temperature and wind velocity oscillations along a gentle slope during sea-breeze events, BoundaryLayer Meteorol., 114, 573-594, 2005.

Campistron, B., Bénech, B., Dessens, J., Jacoby-Koaly, S., Dupont, E., and Carissimo, B.: Performance evaluation of a UHF boundary layer radar in raining conditions based on disdrometer measurements, 8th International Workshop on Technical and Scientific Aspects of MST Radar, Bangalore, India, 1997.

Cros, B., Durand, P., Cachier, H., Drobinski, Ph., Fréjafon, E., Kottmeier, C., Perros, P. E., Peuch, V.-H., Ponche, J.-L., Robin, D., Saï, F., Toupance, G., and Wortham, H.: The ESCOMPTE program: an overview, Atmos. Res., 69, 241-279, 2004.

Delbarre, H., Augustin, P., Saïd, F., Campistron, B., Benech, B., Lohou, F., Puygrenier, V., Moppert, C., Cousin, F., Fréville, P., and Fréjafon, E.: Ground-based remote sensing observation of the complex behaviour of the Marseille's boundary layer during ESCOMPTE, Atmos. Res., 74, 403-433, 2005.

Dessens, J., Bénech, B., Campistron, B., Jacoby-Koaly, S., Dupont, E., and Carissimo, B.: A one year UHF validation campaign using rawinsondings, sodar, anemometers and disdrometer, 8th International Workshop, on Technical and Scientific Aspects of MST Rada, Bangalore, India, 1997.

Gangoiti, G., Millán, M.M., Salvador, R., and Mantilla, E.: Longrange transport and re-circulation of pollutants in the western Mediterranean during the project Regional Cycles of Air Pollution in the West-Central Mediterranean Area, Atmos. Environ., 35, 6267-6276, 2001.
Jacoby-Koaly, S., Campistron, B., Bernard, S., Bénech, B., Girard, F., Dessens, J., Dupont, E., and Carissimo, B.: Turbulent dissipation rate in the boundary layer via UHF wind profiler Doppler spectral width measurement, Boundary-Layer Meteorol., 103, 361-389, 2002.

Kambezidis, H. D., Weidauer, D., Melas, D., and Ulbricht, M.: Air quality in the Athens basin during sea breeze and non sea breeze days using laser remote sensing technique, Atmos. Environ., 32, 2173-2182, 1998.

Kölsch, H. J., Rairoux, P., Wolf, J. P., and Wöste, L.: Comparative study of nitric oxide immission in the cities of Lyon, Geneva and Stuttgart using a mobile differential absorption lidar system, Appl. Phys., B 54, 89-94, 1992.

Lemonsu, A., Bastin, S., Masson, V., and Drobinski, P.: Vertical structure of the urban boundary layer over Marseille under seabreeze conditions, Boundary-Layer Meteorol., 118(3), 477-501, 2006.

Melas, D., Ziomas, I., Klemm, O., and Zerefos, C. S.: Anatomy of the sea-breeze circulation in Athens area under weak large-scale ambient winds, Atmos. Environ., 32, 2223-2237, 1998.

Menut, L., Flamant, C., Pelon, J., and Flamant, P. H.: Urban boundary-layer height determination from lidar measurements over the Paris area, Appl. Opt., 38, 945-954, 1999.

Mestayer, P., Durand, P., Augustin, P., et al.: The Urban Boundary Layer Field Experiment over Marseille UBL/CLU-ESCOMPTE: Experimental Set-up and First Results, Boundary-Layer Meteorol., 114, 315-365, 2005.

Millán, M., Salvador, R., Mantilla, E., and Artnano, B.: Meteorology and photochemical air pollution in Southern Europe: Experimental results from EC research projects, Atmos. Environ., 30, 1909-1924, 1996.

Nazir, M., Khan, F., and Husain, T.: Revised estimates for continuous shoreline fumigation: a PDF approach, J. Hazardous Materials, A118, 53-65, 2005.

Puygrenier, V., Lohou, F., Campistron, B., Saïd, F., Pigeon, G., Benech, B., and Serça, D.: Investigation on the fine structure of sea breeze during ESCOMPTE experiment, Atmos. Res., 74, 329-353, 2005.

Thomasson, A., Geffroy, S., Fréjafon, E., Weidauer, D., Fabian, R., Godet, Y., Nominé, N., Ménard, T., Rairoux, P., Moeller, D., and Wolf, J. P.: LIDAR mapping of ozone-episode dynamics in Paris and intercomparison with spot analysers, Appl. Phys. B, 74, 453459, 2002. 